\title{
SISTEM RESPON LAMPU LALU LINTAS TERHADAP PELANGGARAN PENGENDARA MENGGUNAKAN ULTRASONIK
}

\author{
Muhammad Husni Rifqo, Heni Aprianti2 \\ 1,2Program Studi Informatika, Fakultas Teknik, Universitas Muhammadiyah Bengkulu Jl. Bali PO \\ BOX 118. Telp (0736) 227665, Fax (0736) 26161, Bengkulu 38119
}

Imhrifqo@umb.ac.id; 2heniaprianti@gmail.com

\begin{abstract}
The number of traffic accidents in recent years is very high. In 2013, Gatra magazine recorded as many as 93,578 traffic accidents in Indonesia with 23,385 deaths. The factors causing traffic accidents in Indonesia are: aggressive driving (67\%), over speed (60\%), use of cellphones while driving (37\%), unusual dangerous behavior (45\%), unsafe passing (43\%), drive just for fun (12\%), through traffic lights (72\%). The traffic violation monitoring system at traffic light uses ultrasonic sensors, based on the Arduino Uno, is a tool designed to make it easier for traffic police to detect traffic violations in the traffic light area. The purpose of making this tool is to minimize accidents that often occur because many motorists break through the red light. This research discusses the design of how the ultrasonic sensor works, how this tool works, namely when the red light is on, the ultrasonic sensor is on, so that when a vehicle crosses the red light line, the ultrasonic sensor will send a command to Arduino Uno ordering the buzzer to make a sound., the sound is made in the form of a beep sound.
\end{abstract}

Keyword : Arduino Uno, Ultrasonik, Buzzer

Abstrak - Angka kecelakaan lalu lintas dalam beberapa tahun ini sangat tinggi. Pada tahun 2013 majalah Gatra mencatat sebanyak 93.578 kasus kecelakaan lalu lintas di Indonesia dengan jumlah korban tewas mencapai 23.385 orang. Faktor penyebab terjadinya kecelakaan lalu lintas di Indonesia adalah: aggressive driving (67\%), over speed (60\%), penggunaan HP saat mengemudi (37\%), perilaku berbahaya yang tidak lazim (45\%), unsafe passing (43\%), drive just for fun (12\%), menerobos lampu pengatur lalu lintas (72\%). Sistem pemantauan pelanggaran lalu lintas pada traffic light menggunakan sensor ultrasonik, berbais Arduino Uno adalah suatu alat yang dirancang untuk mempermudah polisi lalu lintas dalam mendeteksi pelanggaran lalu lintas di area traffic light. Tujuan pembuatan alat ini adalah meminimalkan kecelakaan yang sering terjadi dikarenakan banyak pengendara kendaraan yang menerobos disaat lampu merah. Penelitian ini mendiskusikan tentang perancangan cara kerja sensor ultrasonik, cara kerja alat ini yaitu pada saat lampu merah menyala maka sensor ultrasonik on, sehingga ketika ada kendaraan yang melintasi garis batas lampu merah maka sensor ultrasonik tersebut akan mengirimkan perintah kepada Arduino Uno memerintahkan buzzer untuk mengeluarkan suara, suara yang dikeuarkan berupa suara beep.

\section{Kata kunci : Arduino Uno, Ultrasonik, Buzzer}

\section{PENDAHULUAN}

Seiring dengan perkembangan zaman yang juga disertai dengan perkembangan teknologi, jumlah kendaraan yang ada juga terus bertambah banyak, sehingga lalu lintas di jalan juga semakin bertambah padat, perkembangan tersebut membawa dampak yaitu seringnya terjadi pelanggaran dan kecelakaan lalu lintas, salah satunya yaitu pada Traffic Light. Angka kecelakaan lalu lintas dalam beberapa tahun ini sangat tinggi. Pada tahun 2013 majalah Gatra mencatat sebanyak 93.578 kasus kecelakaan lalu lintas di Indonesia dengan jumlah korban tewas mencapai 23.385 orang. Faktor penyebab terjadinya kecelakaan lalu lintas di Indonesia adalah: aggressive driving $(67 \%)$, over speed $(60 \%)$, penggunaan HP saat mengemudi $(37 \%)$, perilaku berbahaya yang tidak lazim (45\%), unsafe passing (43\%), drive just for fun 
(12\%), menerobos lampu pengatur lalu lintas (72\%). Berdasarkan data tersebut, menerobos lampu pengatur lalu lintas menjadi faktor terbesar terjadinya kecelakaan di Indonesia. Fungsi utama lampu lalu lintas adalah untuk mengatur arus lalu lintas yang terpasang di persimpangan jalan agar arus lalu lintas kendaraan tetap lancar. Namun, pengemudi kendaraan seperti tidak mempedulikan adanya lampu lalu lintas tersebut sehingga pemandangan menerobos lampu lalu lintas masih sering terlihat [1]. Banyaknya pengendara kendaraan yang tidak patuh pada rambu lalu lintas membuat POLANTAS ( Polisi Lalu Lintas ) menjadi benar - benar sibuk dalam mengatur ketertipan di area traffic light. Angka kecelakaan di Indonesia menunjukkan peningkatan setiap tahunnya. Angka kecelakaan lalu lintas di ruas jalan seluruh Indonesia pun hingga kini masih tergolong tinggi, dalam beberapa tahun terakhir, kecelakaan lalu lintas di Indonesia oleh Badan Kesehatan Dunia (WHO) dinilai sebagai pembunuh terbesar ketiga, di bawah penyakit jantung koroner dan tuberculosis/TBC. Data WHO tahun 2011 menyebutkan, sebanyak $67 \%$ korban kecelakaan lalu lintas berada pada usia produktif, yakni 22 50 tahun. Terdapat sekitar 400.000 korban di bawah usia 25 tahun yang meninggal di jalan raya, dengan rata-rata angka kematian 1.000 anak-anak dan remaja setiap harinya. Bahkan, kecelakaan lalu lintas menjadi penyebab utama kematian anak-anak di dunia, dengan rentang usia 10-24 tahun [2]

Untuk itu harus ada solusi bagaimana cara agar para pengendara kendaraan akan terkena sangsi saat menerobos traffic light saat lampu merah [3]. Untuk mengatasi hal tersebut dibutuhkan suatu sistem yang dapat mengindentifikasi kendaraan bermotor yang menerobos lampu lalu lintas secara otomatis, Salah satunya dengan memanfaatkan teknologi Ultrasonik. Oleh karena itu pada penelitian ini membahas tentang pemanfaatan teknologi Ultrasonik sebagai pengidentifikasi kendaraan bermotor pelanggar lampu lalu lintas berbasis Arduino Uno. Pada saat sensor ultrsonik mendeteksi objek yang kurang dari $5 \mathrm{~cm}$ maka semua lampu LED pada setiap jalur akan menyala merah sampai objek tersebut tidak terdeteksi oleh sensor Ultrasonik hingga jarak $8 \mathrm{~cm}$. Apabila terdapat pengendara yang menerobos lampu lalu lintas, Ultrasonik akan memberi sinyal dan menghidupkan alarm dan mengeluarkan suara melalui speaker.

\section{LANDASAN TEORI}

\section{A. SISTEM}

Sistem adalah mengandung arti kumpulan, unsur atau komponen yang saling berhubungan satu sama lain secara teratur dan merupakan satu kesatuan yang saling ketergantungan untuk mencapai suatu tujuan. Sedangkan menurut Kamus Besar Bahasa Indonesia Sistem adalah perangkat unsur yang secara teratur saling berkaitan sehingga membentuk suatu totalitas.

Dapat disimpulkan bahwa sistem merupakan kumpulan unsur yang saling berkaitan untuk mencapai tujuan tertentu.

\section{B. RESPON SISTEM}

Respon sistem atau tanggapan sistem adalah perubahan perilaku output terhadap perubahan sinyal input. Respon sistem berupa kurva ini akan menjadi dasar untuk menganalisa karakteristik sistem selain menggunakan persamaan/model matematika.

Bentuk kurva respon sistem dapat dilihat setelah mendapatkan sinyal input. Sinyal input yang diberikan untuk mengetahui karakteristis system disebut sinyal test. Ada 3 tipe input sinyal test yang digunakan untuk menganalisa system dari bentuk kurva response:

a. Impulse signal, sinyal kejut sesaat

b. Step signal, sinyal input tetap DC secara mendadak

c. Ramp signal, sinyal yang berubah mendadak (sin, cos)

Respon sistem atau tanggapan sistem terbagi dalam dua domain/kawasan:

a. Domain waktu (time response)

b. Domain frekuensi (frequency response)

\section{LAMPU LALU LINTAS}

Lampu lalu lintas (menurut UU no. 22/2009 tentang lalu lintas dan angkutan jalan: alat

pemberi isyarat lalu lintas) adalah lampu yang mengendalikan arus lalu lintas yang 
terpasang di persimpangan jalan, tempat penyeberangan pejalan kaki, dan tempat arus lalu lintas lainnya. Lampu ini yang menandakan kapan kendaraan harus berjalan dan berhenti secara bergantian dari berbagai arah. Pengaturan lalu lintas di persimpangan jalan dimaksudkan untuk mengatur pergerakan kendaraan pada masingmasing kelompok pergerakan kendaraan agar dapat bergerak secara bergantian sehingga tidak saling mengganggu antar-arus yang ada. Sistem lalu lintas yang digunakan di seluruh dunia umumnya mempunyai berbagai tujuan, antara lain

1. Menghindari hambatan karena adanya perbedaan arus jalan bagi pergerakan kendaraan

2. Memfasilitasi persimpangan antara jalan utama untuk kendaraan dan pejalan kaki dengan jalan sekunder sehingga kelancaran arus lalu lintas dapat terjamin

3. Mengurangi tingkat kecelakaan yang diakibatkan oleh tabrakan karena perbedaan arus jalan

\section{ARDUINO}

Arduino adalah kit elektronik atau papan rangkaian elektronik open source yang di dalamnya terdapat komponen utama yaitu sebuah chip mikrokontroler dengan jenis AVR dari perusahaan Atmel. Arduino Uno [4] adalah suatu papan elektronik yang mengandung mikrokontroler ATMega328 (sebuah keping yang secara fungsional bertindak seperti sebuah komputer). Piranti ini dapat dimanfaatkan untuk mewujudkan rangkaian elektronik dari yang sederhana hingga yang kompleks. Pengendalian LED hingga pengontrolan robot dapat diimplementasikan dengan menggunakan papan berukuran relatif kecil ini.
Arduino UNO memuat semua yang dibutuhkan untuk menunjang mikrokontroler, mudah menghubungkannya ke sebuah komputer dengan sebuah kabel USB atau mensuplainya dengan sebuah adaptor AC ke DC atau menggunakan baterai untuk memulainya [5]. Bahasa pemrograman Arduino banyak pilihan bahasa pemrograman yang bisa digunakan untuk pemprograman mikrokontroler, misalnya bahasa assembly. Namun dalam pemprograman Arduino bahasa yang dipakai adalah bahasa C. Bahasa C adalah bahasa yang sangat lazim dipakai sejak awal komputer dibuat dan sangat berperan dalam perkembangan software.

Gambar 2. 1 Arduino UNO

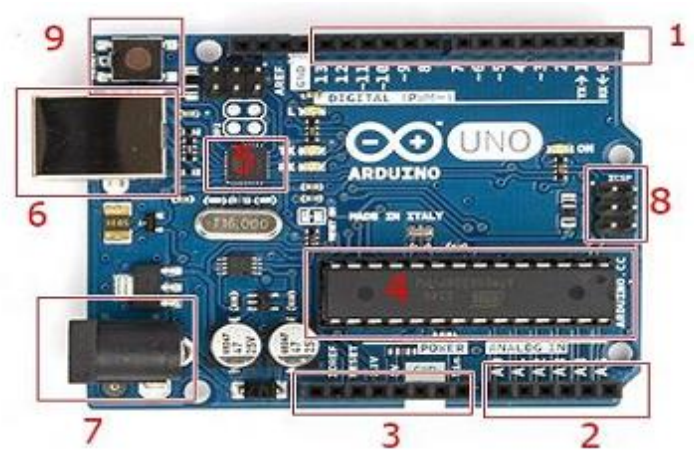

Penjelasan [6]:

1. Pin input/output digital

Secara umum pin I/O ini adalah pin digital, yakni pin yang bekerja pada level tegangan digital (0V sampai 5V) baik untuk input atau output.namaun pada bebrapa pin output analog, yang dapat mengeluarkan tegangan analog $0 \mathrm{~V}$ sampai $5 \mathrm{~V}$, pin tersebut adalah pin 3,5,6,9,10 dan 11, selain itu untuk pin 0 dan 1 juga memiliki fungsi khusus sebagai pin komunikasi serial.

2. Pininput analog

Pin tersebut dapat memrima input tegangan analog antara $0 \mathrm{~V}$ sampai $5 \mathrm{~V}$, tegangan ini akan direpresentasikan sebagai bilangan 0 1023 dalam program.

3. Pin untuk sumber tegangan

Kelompok pin ini merupakan kumpulan pin yang berhubungan dengan sumber tenaga, missalnya output $5 \mathrm{~V}$, Output $3,3 \mathrm{~V}$, GND (2 pin) dan Vref (tegangan referensi untuk pembacaan ADC internal)

4. IC ATMega328 
pusat kendali pemrosesan data

5. IC ATMega16U

menangani komunkasi data dengan PC melalui port USB

6. Jack USB

Merupakan soket USB tipe B sebagai penghubung data serial dengan PC

7. Jack Power

Merupakan Soket untuk catu daya eksternal antara 9V samai $12 \mathrm{~V}$ DC

8. Port ICSP (In-Circuit Serial Programing)

Port ini digunakan untuk memprogram arduino tanpa bootloader

9. Tombol Reset

Digunakan untuk mereset papan mikrokontroller arduino untuk memulai program dari awal

\section{E. SENSOR ULTRASONIK}

Sensor Ultrasonik HC-SR04 adalah modul sensor yang dapat membaca jarak dengan rentang $2 \mathrm{~cm}$ sampai dengan $400 \mathrm{~cm}$. Sensor ultrasonik bekerja dengan cara memancarkan gelombang suara ultrasonik sesaat dan kemudian akan menghasilkan outut berupa pulsa yang sesuai dengan waktu pantulan dari gelombang ultrasonik yang dipancarkan sesaat kemudian kembali menuju sensor [7].

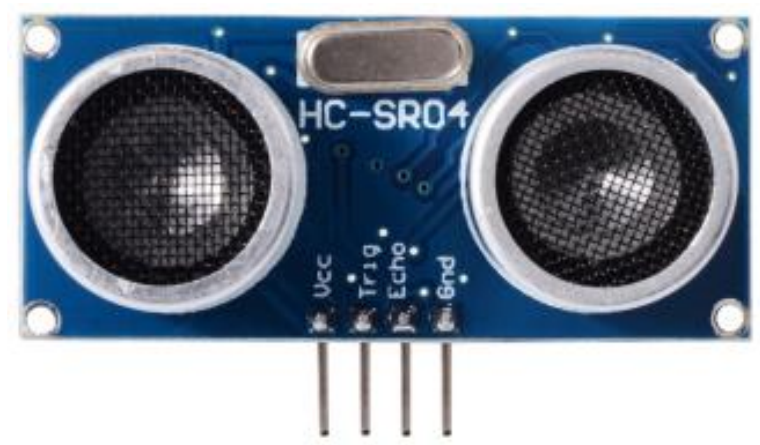

Gambar 2. 2 Ultrasonik

\section{F. LED (Light Emitting Diode)}

Light Emitting Diode atau sering disingkat dengan LED adalah komponen elektronika yang dapat memancarkan cahaya monokromatik ketika diberikan tegangan maju. LED merupakan keluarga Dioda yang terbuat dari bahan semikonduktor. Warna-warna Cahaya yang dipancarkan oleh LED tergantung pada jenis bahan semikonduktor yang dipergunakannya. LED juga dapat memancarkan sinar inframerah yang tidak tampak oleh mata seperti yang sering kita jumpai pada Remote Control TV ataupun Remote Control perangkat elektronik lainnya.

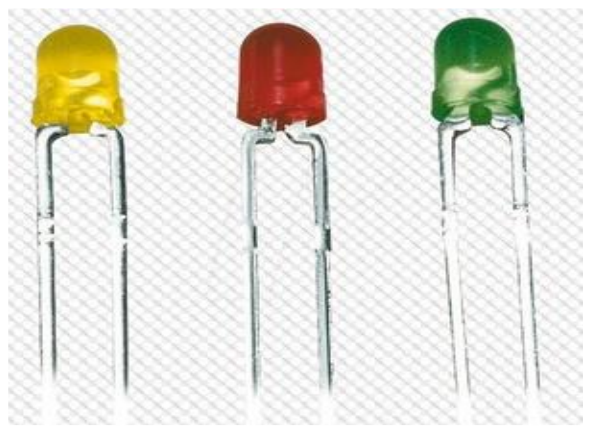

\section{Gambar 2. 3 LED Kuning, Merah dan Hijau}

Bentuk LED mirip dengan sebuah bohlam (bola lampu) yang kecil dan dapat dipasangkan dengan mudah ke dalam berbagai perangkat elektronika. Berbeda dengan Lampu Pijar, LED tidak memerlukan pembakaran filamen sehingga tidak menimbulkan panas dalam menghasilkan cahaya. Oleh karena itu, saat ini LED (Light Emitting Diode) yang bentuknya kecil telah banyak digunakan sebagai lampu penerang dalam LCD TV yang mengganti lampu tube.

\section{METODE PENELITIAN}

\section{A. Metode Pengumpulan Data}

Dasar penelitian yang digunakan sebagai bahan untuk kelengkapan data dan informasi adalah:

1. Studi Pustaka

Pengumpulan data yang dilakukan oleh peneliti dengan mengumpulkan data yang berasal dari bahan pustaka seperti buku tentang mikrokontroler, arduino, serta jurnal tentang alat. Pustaka juga diperoleh dengan mengunduh bahan seperti artikel dan jurnal dari internet.

2. Wawancara

Pengumpulan data yang dilakukan oleh peneliti dengan mengadakan wawancara atau tanya jawab secara langsung dengan praktisi robotik yaitu Yeni Fusfa Dewi, S.Kom.

\section{B. ANALISIS SISTEM}

1. Flowchart 
Flowchart adalah suatu bagan dengan simbol tertentu yang menggambarkan urutan proses secara mendetail dan hubungan antara suatu proses dengan proses lainnya dalam suatu program. Flowchart digunakan untuk membantu programer dalam memecahkan masalah.

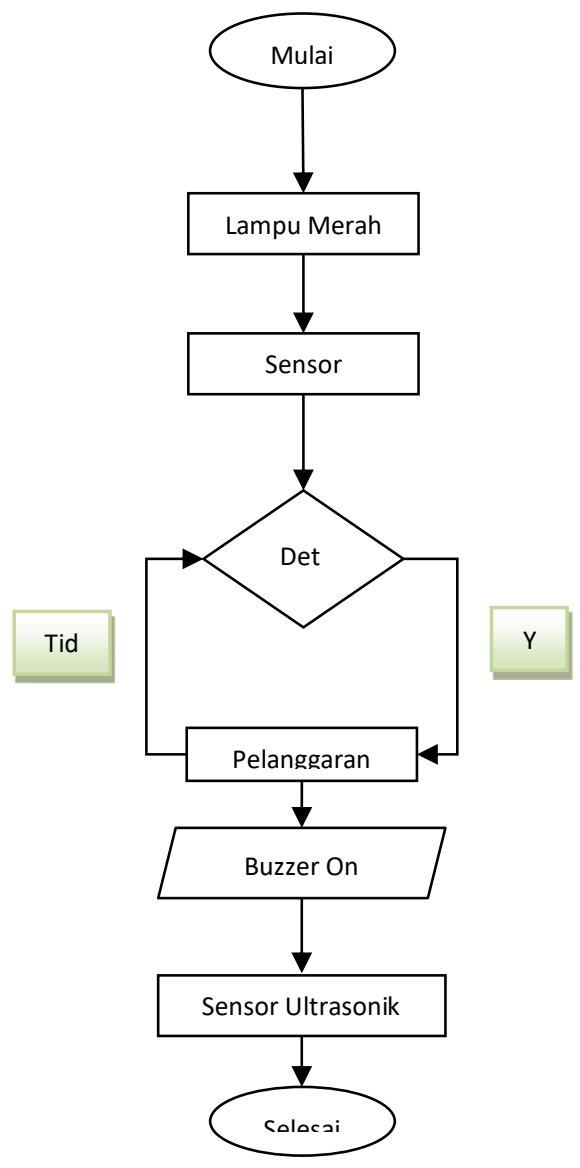

\section{Gambar 3. 1 Flowchart Sistem Kerja Sensor Ultrasonik}

\section{Perancangan Skema Rangkaian}

Perancangan skema rangkaian meliputi tahapan pengerjaan yang merupakan bagian inti dari alat. Dalam perancangan ini yang perlu diperhatikan adalah pemilihan komponen-komponen yang digunakan. Pemilihan komponen harus disesuaikan dengan kebutuhan sesuai dengan desain alat yang akan dibuat.
Adapun perancangan skema rangkaian yang akan dibuat adalah sebagai berikut :

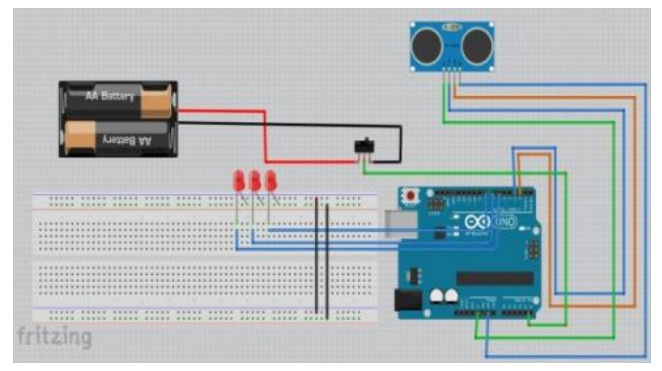

Gambar 3. 2 Rancangan Skema Sistem Respon Lalu Lintas

Dari hasil skema diatas maka dirancang sebuah penempatan pada perangkat keras yang berupa sensor-sensor, mikrokontroler Arduino Uno dan LED.

\section{HASIL DAN PEMBAHASAN}

Sistem respon lampu lalu lintas yang telah dibuat secara keseluruhan sudah sesuai dengan rancangannya dan sudah dilakukan pengujian alat secara menyeluruh. Berikut ini adalah penjelasan dari hasil yang didapat:

\section{Perancangan Alat}

Pembuatan sistem respon lampu lalu lintas ini melalui beberapa tahap pembuatan. Dimulai dengan mempersiapkan bahan dan alat yang digunakan seperti menyiapkan arduino uno, bradboard, resistor, baterai, buzzer, LED dan sensor ultrasonik. Tujuan dari pembuatan yaitu sebagai wadah sistem respon lampu lalu lintas ini dapat digunakan dan dijalankan sesuai fungsinya. Proses selanjutnya yaitu pembuatan rangkaian.

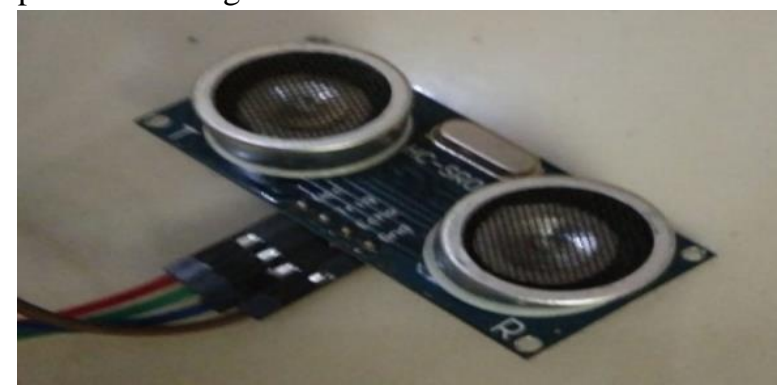


Gambar 4. 1 Sensor Ultrasonik

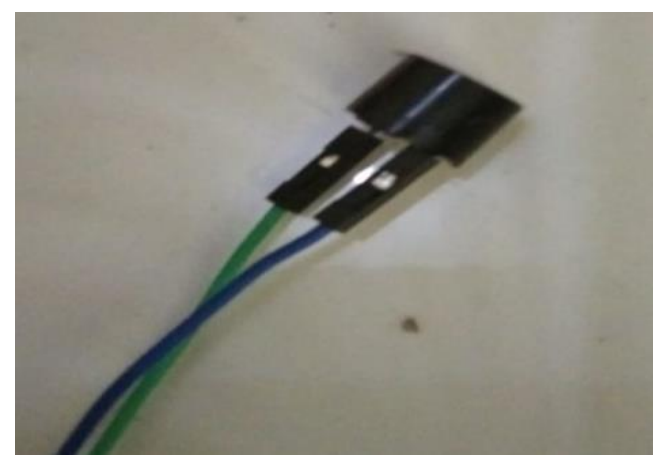

Gambar 4. 2 Buzzer

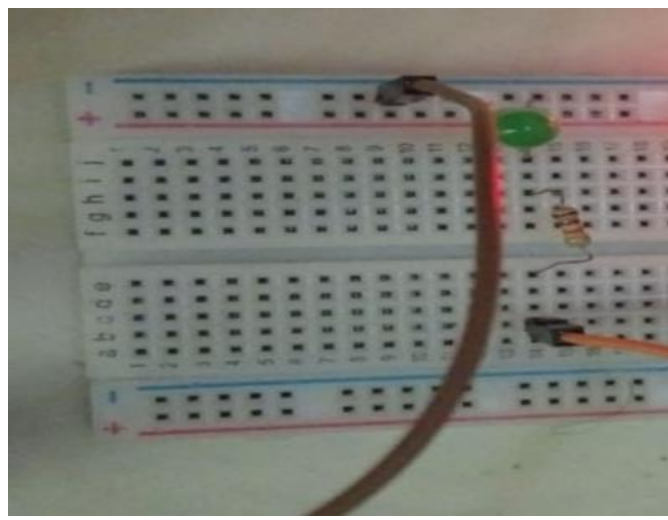

Gambar 4. 3 Papan Bradboard

2. Pembuatan Rangkaian

Pada tahap pembuatan rangkaian yang dilakukan adalah mempersiapkan komponen yang akan digunakan seperti mikrokontroler arduino, batterai, buzzer, LED dan sensor ultrasonik. Pada arduino sudah disematkan mikrokontroler Atmega 328 yang memiliki 14 pin input/output digital (6 output untuk PWM), dan 6 pin analog input.

Rangkaian elektronik arduino memiliki beberapa komponen lainnya seperti IC regulator yang berfungsi sebagai kebutuhan rangkaian power supply. Sebagai sumber tegangan dalam rangkaian ini menggunakan baterai. Untuk rangkaian sensor Ultrasonik adalah modul sensor yang dapat membaca jarak dengan rentang $2 \mathrm{~cm}$ sampai dengan 400 $\mathrm{cm}$. Arduino uno memiliki 14 pin digital pin input/output yang mana 6 pin dapat digunakan sebagai output PWM, 6 analog input, crystal osilator $16 \mathrm{MHz}$, koneksi USB, jack power, kepala ICSP dan tombol riset. Hal tersebut yang diperlukan untuk mendukung sebuah rangkaian mikrokontroler. Sebuah LED membutuhkan arus sekitar $20 \mathrm{~mA}$ untuk memancarkan cahaya dengan kecerahan maksimum, meskipun arus kecil 5mA pun masih dapat menghasilkan cahaya yang jelas tampak. Jatuh tegangan maju sebuah LED rata-rata adalah $1,5 \mathrm{~V}$, sehingga pasokan tegangan $2 \mathrm{~V}$ dapat menyalakan sebagian besar LED dengan kecerahan maksimum. Dengan level-level tegangan yang lebih tinggi, LED dapat terbakar apabila tegangan maju yang diberikan melebihi $2 \mathrm{~V}$. Maka diharuskan menyambungkan resistor pembatas arus ke sebuah LED

3. Rancangan Program

Rancangan Sistem respon lampu lalu lintas ini terdiri dari beberapa langkah. Langkah pertama adalah pembuatan flowchart dari robot. Kemudian program dibuat menggunakan Arduino IDE menggunakan bahasa C. Program inilah yang akan menjalankan perintah-perintah pada sistem dan alat. Kemudian program diunggah ke mikrokontroler menggunakan Arduino. Selanjutnya mikrokontroler akan melakukan proses pembacaan sensor ultrasonik.

4. Implementasi

Setelah sistem dibangun berdasarkan rancangan yang telah dibuat maka langkah berikutnya adalah melakukan upload program dengan langkah-langkah sebagai berikut :

a) Hubungkan kabel USB dengan board arduino uno dan pada sisi lainnya dihubungkan dengan komputer

b) Buka program Arduino kemudian open sketch program pada robot yang telah dibuat

c) Tekan tombol upload pada Arduino agar sketch ditransfer dari komputer ke board arduino

d) Setelah selesai melakukan upload, maka kabel USB dapat dilepas dan alat dapat bekerja tanpa bantuan komputer lagi 
e) Lampu LED merah menyala maka sensor ultrasonik dalam keadaan on untuk mendeteksi jangkauan area yang telah diprogram

f) Apabila ada objek yang terdeteksi dari jangkauan sensor ultrasonik maka buzzer akan menyala secara otomatis untuk memberitahukan pada pengendara agar pengendara menyadari bahwa pengendara tersebut sudah melanggar

g) Apabila LED hijau kembali menyala maka sensor ultrasonik dalam keadaan off dan pengendara bisa melewati tanpa melanggar

5. Pengujian Sistem

Pengujian ini dilakukan menggunakan peraga simulasi prototype. Cara kerja robot yaitu dengan menghubungkan ke sumber daya dan tekan tombol on/off. Pada robot ini mikrokontroler bekerja dengan menjalankan perintah yang telah di input-kan sebelumnya berupa coding, dimana coding tersebut mewakili perintah untuk menjalankan sensor ultrasonik dan arduino uno. Sehingga menghasilkan output sesuai dengan kondisi yang terdeteksi oleh sensor. Pengujian pada robot ini bertujuan untuk melihat apakah sensor ultrasonik, arduino dan program telah berjalan dengan baik.

Pengujian ultrasonik dilakukan dengan cara membaca jarak objek dengan jangkauan yang telah ditentukan. Pengujian ini dilakukan sebanyak 2 kali putaran untuk menguji jarak baca sensor agar dapat mendeteksi pelanggar. Kemudian untuk mengetahui tingkat keberhasilan dalam mendeteksi pelanggaran pengendara dilakukan oleh penulis.

Robot ini telah diprogram untuk terus berjalan dan berhenti apabila ada pelanggaran terhadap traffic light. Robot ini memiliki speed sebesar 200 PWM. Dan speed maksimal sebesar 250 PWM. Namun robot ini bisa saja berhenti secara tiba-tiba dikarenakan sensor tidak mampu membaca jarak objek. Adapun penyebab dari eror tersebut bisa saja berasal dari robot atau program robot itu sendiri. Eror pada robot bisa saja terjadi akibat lemahnya catu daya pada robot atau kerusakan pada kabel maupun pin-pin yang tidak diketahui. Ketika robot tiba-tiba mengalami eror dan berhenti maka robot akan on kembali dalam jangka waktu lebih kurang 10 detik tanpa harus menekan lagi tombol on/off pada robot. Pada percobaan yang dilakukan yaitu robot mendeteksi objek hanya dengan jarak $5 \mathrm{~cm}$ saja. Apabila jarak robot dan objek lebih dari tersebut maka sensor tidak akan mampu membaca objek atau mengalami eror dikarenakan terlalu jauh. Dan apabila jarak robot dengan objek misalnya $1-5 \mathrm{~cm}$ maka robot akan sulit untuk membaca dikarenakan terlalu dekat sehingga menyebabkan robot berhenti atau eror

6. Hasil Pengujian

Adapun hasil dari pengujian adalah sebagai berikut:

\section{Tabel 4. 1 Hasil Pengujian}

\begin{tabular}{|l|l|}
\hline \multicolumn{1}{|c|}{ Kegiatan } & \multicolumn{1}{|c|}{ Hasil } \\
\hline $\begin{array}{l}\text { LED merah } \\
\text { menyala }\end{array}$ & $\begin{array}{l}\text { Sensor } \text { ultrasonik on dan mampu membaca } \\
\text { ada pelanggaran atau tidak. }\end{array}$ \\
\hline $\begin{array}{l}\text { Kendaraan } \\
\text { melanggar }\end{array}$ & $\begin{array}{l}\text { Sensor ultrasonik memberi perintah } \\
\text { melalui arduino uno untuk memberikan } \\
\text { informasi berupa suara beep pada } \text { buzzer. }\end{array}$ \\
\hline $\begin{array}{l}\text { LED hijau } \\
\text { menyala }\end{array}$ & Sensor ultrasonik off. \\
\hline
\end{tabular}

\section{KESIMPULAN DAN SARAN}

\section{A. KESIMPULAN}

Setelah melakukan perancangan dan pengujian terhadap alat secara keseluruhan. Maka dapat diambil kesimpulan :

1. Perangkat yang dibuat oleh penulis dapat bekerja dengan baik sesuai dengan yang diharapkan

2. Sensor ultrasonik dapat mendeteksi adanya pelanggaran pengendara pada prototype saat LED menyala

3. Sensor ultrasonik juga dapat membaca jarak batas $1-5 \mathrm{~cm}$.

4. Pada saat LED hijau kembali menyala maka sensor ultrasonik otomatis off.

5. Mikrokontroler arduino uno yang digunakan sebagai pengendali utama dapat bekerja dalam menjalankan perintah yang diberikan 


\section{B. SARAN}

Untuk penelitian selanjutnya diharapkan dapat mengembangkan atau menciptakan sebuah sistem dengan harapan agar menjadi lebih baik, dan sebagai sara kedepan:

1. Untuk pengembangan sistem dapat ditambahkan lcd agar pada saat sensor telah mendeteksi maka no kendaraan akan terbaca di lcd tersebut.

2. Untuk mempermudah pekerjaan polisi sistem dapat menggunakan sms menggunakan android agar no kendaraan otomatis terkirim pada ponsel polisi terdekat

\section{DAFTAR PUSTAKA}

[1] A. Sumantri, E. D. Meutia dan S. Muchallil, "Rancang Bangun Purwarupa Pengidentifikasi," KITEKTRO: Jurnal Online Teknik Elektro, vol. 1, no. 1, pp. 19-24, 2016.

[2] A. Hidayah, "ENSIKLOPEDIA TRAFFIC SIGNS; SOLUSI CERDAS," Jurnal PENA, vol. 4, no. 1, pp. 688-700, 2017.

[3] A. B. Nugroho, "Sistem Pemantau Pelanggaran Lalu Lintas Pada Traffic Light," ELKOM "Jurnal Teknik Elektro Dan Komputasi”, vol. 1, no. 1, pp. 18-26, 2019.

[4] A. Kadir, Panduan Peraktis, Yogyakarta: Andi Offset, 2013.

[5] M. Ichwan, M. G. Husada dan M. I. Ar Rasyid, "PEMBANGUNAN PROTOTIPE SISTEM PENGENDALIAN PERALATAN," JURNAL INFORMATIKA, vol. 4, no. 1, pp. 1325, 2013.

[6] Bahrin, "SISTEM KONTROL PENERANGAN MENGGUNAKAN ARDUINO," ILKOM Jurnal IImiah, vol. 9, no. 3, pp. 282-289, 2017.
[7] S. Budiyanto, M. K. Baidin dan F. Rahayu, "Rancang Bangun Pendeteksi Kendaraan Pada Yellow Box Junction Berbasis Arduino MEGA 2560 Dengan Sensor Ultrasonik," dalam Seminar Nasional Teknik Elektro 2018, Malang, 2018. 